\title{
Gastric Mucosal Protective Action of Nicorandil against Gastric Lesions Induced by Indomethacin
}

\author{
Selim M Abdel-Hakim* and Salama R. Abdel-Raheem** \\ Departments of Physiology* and Biochemistry**, \\ Faculty of Medicine, El-Minia University
}

\begin{abstract}
The present investigation was an attempt to evaluate the anti-ulcer activity of nicorandil in indomethacin-induced ulcer model. The drugs selected in that investigation included: nicorandil ( $K_{\text {ATP }}$ channel opener), glabinclamide $\left(K_{A T P}\right.$ channel blocker), cimetidine and indomethacin. Male albino rats weighing 150-200 grams were fasted for 24 hours prior to the experiment. Pyloric ligation was performed 2 hours after indomethacin administration. Rats were randomly divided into the following groups of 10 rats each: Control (C) group, non pretraeted indomethacin (I) group, cimetidine pre-treated (CI), tween 80 pre-treated (TI), glibenclamide pretreated (GI), nicorandil pre-treated (NI) and nicorandil + glibencalamid pre-treated (NGI) indomethacin groups. After 5 hours from indomethacin administration (and 3 hours from pyloric ligation), rats were sacrificed. Their stomachs were removed, opened along the greater curvature and the gastric contents were collected for analysis of gastric juice parameters (volume, $\mathrm{pH}$, total and free acid concentration, pepsin concentration and mucin concentration). The stomachs were washed with ice-cold saline and scored for macroscopic gross mucosal lesions. The stomachs were washed with indomethacin and stored at $-80^{\circ} \mathrm{C}$ until used for assessment of gastric mucosal lipid peroxides, histamine, $P G E_{2}$ and nitrites. Results: Ulcerative lesions were observed in indomethacin treated rats where the ulcer index (UI) mounted to $18.1 \pm 1.04$. Nicorandil significantly protected rats against gastric ulceration. Indomethacin insignificantly altered gastric juice volume, $\mathrm{pH}$, total and free acid concentration, pepsin and mucin concentration. Cimetidine significantly protected rats from gastric mucosal ulceration, and significantly reduced gastric juice volume. Pretreatment with glibenclamide did not alter gastric lesion UI while it significantly increased gastric juice volume, free and total acid concentration. Co-administration of glibenclamide with nicorandil significantly decreased gastric juice $\mathrm{pH}$ and mucin concentration and significantly increased gastric juice volume, free and total acid concentration. The increase in gastric mucosal histamine and nitrite contents observed with nicorandil was not affected by co admistration of glibenclamide with it. Conclusion: nicorandil significantly protected gastric mucosa from indomethacin-induced lesion. The mechanism underlying that protection involves mainly $K_{A T P}$ channel opening, leading to decreased gastric acid secretion and proteolytic activity, NO donation, reduction of lipid peroxidation and normalization of the detrimental elevation of gastric mucosal nitrites level. Histamine and $P G E_{2}$ do not seem to contribute to nicorandil's gastroprotective effects.
\end{abstract}

Key Words: Nicorandil, gastric mucosa, indomethacin, cimetidine, glibenclamide, ulcer index. 


\section{INTRODUCTION}

Peptic ulcers are common and represent a health problem, both in terms of human suffering and in cost to society in forms of lost productivity and requirement for health care resources. Its incidence is increasing due to rapid development and civilization constrains. The estimates of peptic ulcer incidence vary ranging from $3 \%$ to $10 \%$ worldwide. Numerous classes of drugs were tested for their ulcer-protective activity, including modulators of ion channels, like calcium and potassium channels, benefiting from the great advances in the field of molecular pharmacology and the new insights discovered about the role of these ion channels in gastrointestinal tract physiology ${ }^{1}$.

Several chemical mediators were found to play a role in the gastrointestinal tract. Special attention was given to nitric oxide (NO) and prostaglandins (PGs). White et al. ${ }^{2}$ reported that $\mathrm{NO}$ was implicated in the modulation of gastric mucosal integrity together with endogenous PGs. Histamine, also, is another chemical mediator in the stomach. It is a remarkably powerful gastric secretagogue and is involved in the pathogenesis of peptic ulcer, as administration of histamine or compounds that cause its release produce peptic ulcer in experimental animals ${ }^{3}$.

\section{Aim of the Work:}

The present investigation was an attempt to evaluate the anti-ulcer activity of nicorandil in indomethacininduced ulcer model. In addition, the role of $\mathrm{K}_{\mathrm{ATP}}$ channels and possible involvement of some chemical mediators; namely; histamine, lipid peroxides, NO and PGs, as targets for the ulcer-protective action of nicorandil were investigated.

\section{MATERIAL \& METHODS}

All chemicals were obtained commercially and were of the highest available purity. Glibenclamide was suspended in $1 \%$ tween 80 . All other drugs were dissolved in saline. Drug doses, as well as, the dosage schedules were selected on the basis of the previous studies $^{3-7}$.

Animals:

The present study was conducted on 70 adult male albino rats weighing 150-200 grams.

Experimental Procedure:

Rats were fed a standard diet of commercial rat chow and tap water. Rats were fasted for 24 hours prior to the experiment in mesh bottomed cages to minimize coprophagia. Except for the last hour, water was supplied ad libitum ${ }^{8}$. All experiments were performed during the same time of the day to avoid variations due to diurnal rhythms of putative regulators of gastric functions.

Rats were pylorically ligated under light ether anesthesia'. Rats were allowed to recover from anesthesia for about 5 minutes. Rats were randomly divided into the following groups of 10 rats each:

1. Control group (C); in which animals were left freely wandering in their cages for 3 hours after being subjected to pyloric ligation.

2. Indomethacin group (I); in which rats received no further medication 
other than indomethacin $(40 \mathrm{mg} / \mathrm{kg}$, S.C.).

3. Cimetidine pretreated Indomethacin group (CI); in which cimetidine $(50 \mathrm{mg} / \mathrm{kg}$, I.P.) was administered 30 minutes prior to administration of indomethacin.

4. Tween $80 \quad$ pretreated Indomethacin group (TI); in which $1 \%$ solution of tween 80 ( $1 \mathrm{ml} / \mathrm{kg}$, I.P.) was administered one hour prior to administration of indomethacin.

5. Glibenclamide pretreated Indomethacin group (GI); in which glibenclamide (6 mg/kg, I.P.) suspended in tween 80 was administered one hour prior to administration of indomethacin.

6. Nicorandil pretreated Indomethacin group (NI); in which nicorandil (10 mg/kg, I.P.) was administered 30 minutes prior to administration of indomethacin.

7. Glibenclamide and Nicorandil pretreated Indomethacin group (GNI); in which glibenclamide (6 $\mathrm{mg} / \mathrm{kg}$, I.P.) was injected. After 30 minutes, nicorandil (10 mg/kg, I.P.) was injected then indomethacin administration was given 30 minutes later.

After completion of the 5 hours after indomethacin administration (including pyloric ligation for the last 3 hours), rats were killed by an over dose of ether. Their stomachs were removed and opened along the greater curvature and gastric contents of each stomach was collected. The stomachs were washed with ice-cold saline and scored for macroscopic gross mucosal lesion, washed with indomethacin (10 $\mu \mathrm{g} / \mathrm{ml}$ ) and stored at $-80{ }^{\circ} \mathrm{C}$ until used for assessment of gastric mucosal lipid peroxides, histamine, $\mathrm{PGE}_{2}$ and NO. immediately before assay, the gastric mucosa was scrapped, homogenized, centrifuged and the supernatant was used to assay $\mathrm{PGE}_{2}$ and NO.

\section{Assessment of gastric mucosal lesions:}

Gastric mucosal lesions were expressed in terms of the ulcer index (UI) according to the method of Peskar et al. ${ }^{10}$.

Gastric mucosal (GM) parameters Determination:

1. Determination of GM lipid peroxides: This was done by assay of the concentration of thiobarbituric acid reactive substances (TBARS) referred to as malodialdehyde (MDA) ${ }^{\mathbf{1 1}}$.

2. Determination of GM histamine: by a spectrophotometric method ${ }^{12}$.

3. Determination of GM PGE 2 : by an enzyme immunoassay kit.

4. Determination of GM NO: based on colorimetric detection of nitrite using an enzyme immunoassay $\mathrm{kit}^{13}$.

Collection and analysis of gastric juice:

Gastric juice was collected and centrifuged for 15 minutes at 3000 $\mathrm{rpm}$ to remove any solid debris and the volume of the supernatant was determined. Then the supernatant was analyzed for the following parameters: 1. Determination of $\mathrm{pH}$ of the gastric juice; the $\mathrm{pH}$ of the gastric juice was determined according to Moore $^{14}$.

2. Determination of the acid concentration of GJ according to the method described by Hara et al. ${ }^{15}$. 
3. Determination of the proteolytic activity of GJ by spectrophotometric method $^{\mathbf{1 6}}$.

4. Determination of the mucin according to the method reported by Bhavanandan et al. ${ }^{17}$.

\section{Statistical Analysis of Data:}

Data were expressed as mean \pm standard error of the mean $(\mathrm{M} \pm$ SEM). Statistical significance of differences between groups were evaluated by unpaired two-tailed Student's " $t$ " test. Values of $p<0.05$ were considered statistically significant.'

\section{RESULTS}

I- Effect Of Indomethacin On Gastric Lesion Development And Its Alteration By Various PreTreatments:

Administration of indomethacin induced ulcerative lesions in $96 \%$ of rats. The UI was $18.1 \pm 1.04$. IP administration of cimetidine prior to indomethacin ameliorated gastric lesion development and significantly decreased the UI to $6.17 \pm 0.24$. Nicorandil protected against indomethacin-induced ulceration more significantly than cimetidine, achieving an ulcer index of $2.42 \pm$ 0.15. Meanwhile, glibenclamide, insignificantly altered the ulcer index. Co-administration of glibenclamide with nicorandil didn't completely abolish the protective effect of nicorandil, but significantly increased the ulcer index to $13.8 \pm 1.03$ (table 1). II- Effect of Indomethacin on Gastric Juice Parameters and Its Alteration by Various PreTreatments:

\section{Volume of gastric secretion}

Indomethacin administration insignificantly altered the volume of gastric juice as compared to the $\mathrm{C}$. Pretreatment with cimetidine reduced significantly gastric juice volume. On the other hand, nicorandil insignificantly affected gastric juice volume. Glibenclamide pretreatment significantly increased gastric juice volume as compared to I and amounted to $2.29 \pm 0.18 \mathrm{~m} / 3 \mathrm{hrs}$. Coadministration of glibenclamide with nicorandil significantly increased gastric juice volume as compared to NI (table 2).

\section{2. pH of gastric juice:}

Indomethacin did not significantly alter gastric juice $\mathrm{pH}$ as compared to the $\mathrm{C}$; neither did cimetidine nor nicorandil. Pretreatment with glibenclamide significantly decreased gastric juice $\mathrm{pH}$ as compared to I. Combined administration of glibenclamide with nicorandil significantly reduced gastric juice $\mathrm{pH}$ as compared to NI or I (table 3).

3. Gastric juice free and total acid concentrations (FAC \& TAC):

Indomethacin insignificantly altered the FAC and TAC as compared to $\mathrm{C}$. Cimetidine and nicorandil insignificantly altered both FAC and TAC as compared to I. Conversely, pretreatment with glibenclamide and co-administration of glibenclamide with nicorandil significantly increased both FAC and TAC as compared to C, I, CI and NI groups (table 4).

4. Gastric juice pepsin
concentrations:
Neither indomethacin nor
any of the pretreatments were able to


produce any significant alteration in the gastric juice pepsin as compared to control group (table 5).

\section{Gastric juice mucin concentrations:}

Indomethacin, cimetidine and nicorandil pre-treatments insignificantly affected gastric juice mucin concentration. Conversely, glibenclamide pretreatment and combined administration of glibenclamide and nicorandil significantly reduced mucin concentration as compared to $\mathrm{C}, \mathrm{I}, \mathrm{CI}$ and NI groups (table 6).

III. Effect of indomethacin on gastric mucosal content of lipid peroxides and its alteration by various pretreatments

Neither indomethacin nor any of the pretreatments was able to induce any significant difference in gastric mucosal lipid peroxides content (table 7).

IV. Effect of indomethacin on gastric mucosal content of histamine and its alteration by various pretreatments

Groups pre-treated with nicorandil alone and in combination with glibenclamide showed significant elevation in histamine content reaching a value of $231 \pm 18.2$ and
$227 \pm 7.3 \mu \mathrm{g} / \mathrm{g}$ wet tissue respectively in comparison to I (table 8).

V. Effect of indomethacin on gastric mucosal $\mathrm{PGE}_{2}$ and its alteration by various pretreatments

Indomethacin administration significantly reduced gastric mucosal $\mathrm{PGE}_{2}$ content from $346 \pm 33 \eta \mathrm{g} / \mathrm{g}$ wet tissue for the control group to $233 \pm$ $21.4 \mathrm{\eta g} / \mathrm{g}$ wet tissue. None of the pretreatments was able to significantly alter gastric juice $\mathrm{PGE}_{2}$ content in comparison to the non-pretreated indomethacin group (table 9).

VI. Effect of indomethacin on. the total gastric mucosal nitrites content of and its alteration by various pretreatments

Indomethacin, cimetidine and glibenclamide administration did not significantly alter gastric mucosal nitrites content as compared to the control group. On the other hand, nicorandil significantly increased gastric mucosal nitrites content from $165 \pm 10.9 \mathrm{\eta mol} / \mathrm{g}$ wet tissue, for I, to $249 \pm 20 \eta \mathrm{mol} / \mathrm{g}$ wet tissue in NI. Coadministration of glibenclamide with nicorandil significantly increased gastric mucosal nitrites reaching 253 $\pm 24.9 \eta \mathrm{mol} / \mathrm{gm}$ wet tissue as compared to I (table 10). 
TABLE (1): Effect of indomethacin (40 mg/kg, SC) on gastric lesion development and its alteration by various pre-treatments.

\begin{tabular}{|l|l|l|l|}
\hline Group & \% incidence & Ulcer Index & Preventive Index \% \\
\hline C & $\mathbf{0}$ & $\mathbf{0}$ & \\
\hline I & $\mathbf{9 6 . 0}$ & $\mathbf{1 8 . 1} \pm \mathbf{1 . 0 4}^{\mathbf{a}}$ & $\mathbf{0}$ \\
\hline CI & $\mathbf{7 9 . 0}$ & $\mathbf{6 . 1 7} \pm \mathbf{0 . 2 4}^{\mathbf{b}}$ & $\mathbf{6 5 . 9}$ \\
\hline TI & $\mathbf{9 1 . 3}$ & $17.7 \pm \mathbf{1 . 2 7}$ & $\mathbf{2 . 2 1}$ \\
\hline GI & $\mathbf{1 0 0}$ & $\mathbf{2 1 . 4} \pm \mathbf{0 . 7 9}$ & $\mathbf{- 1 8 . 2}$ \\
\hline NI & $\mathbf{6 9 . 2}$ & $\mathbf{2 . 4 2} \pm \mathbf{0 . 1 5}^{\mathbf{a}, \mathbf{b}, \mathbf{c}}$ & $\mathbf{8 6 . 6}$ \\
\hline NGI & $\mathbf{9 3 . 8}$ & $\mathbf{1 3 . 8}^{\mathbf{a}, \mathbf{1 . 0 3}}$ & $\mathbf{2 3 . 8}$ \\
\hline
\end{tabular}

$C=$ control group, $I=$ indomethacin group, $C I=$ cimetidine pretreated indomethacin group, $T I=$ tween 80 pretreated indomethacin group, $G I=$ glibenclamide pretreated indomethacin group, $N I=$ nicorandil pretreated indomethacin group and NGI = nicorandil and glibenclamide pretreated indomethacin group. $a=$ significantly different from $C, b=$ significantly different from $I, c=$ significantly different from $C I$, $d$ = significantly different from NI. Values represent the mean \pm SEM for 10 observations.

TABLE (2): Effect of indomethacin (40 mg/kg, SC) on gastric juice volume and its alteration by various pre-treatments.

\begin{tabular}{|l|c|}
\hline GROUP & GASTRIC JUICE VOLUME (ml/3 hours) \\
\hline C & $0.91 \pm 0.07$ \\
\hline I & $1.35 \pm 0.09$ \\
\hline CI & $0.80 \pm 0.07^{\mathbf{b}}$ \\
\hline TI & $1.53 \pm 0.15$ \\
\hline GI & $2.29 \pm 0.18^{\mathbf{a}, \mathbf{b}, \mathbf{c}}$ \\
\hline NI & $1.33 \pm 0.13$ \\
\hline NGI & $2.03 \pm 0.17^{\text {a,c,d }}$ \\
\hline
\end{tabular}

$C=$ control group, $I=$ indomethacin group, $C I=$ cimetidine pretreated indomethacin group, $T I=$ tween 80 pretreated indomethacin group, $G I=$ glibenclamide pretreated indomethacin group, NI = nicorandil pretreated indomethacin group and NGI = nicorandil and glibenclamide pretreated indomethacin group. $a=$ Significantly different from $C$ at $p<0.05, b=$ Significantly different from $I$ at $p<0.05, c=$ Significantly different from CI at $p<0.05$ and $d=$ Significantly different from NI at $p<0.05$. Values represent the mean \pm SEM for 10 observations. 
TABLE (3): Effect of indomethacin (40 mg/kg, SC) on gastric juice $\mathrm{pH}$ and its alteration by various pre-treatments

\begin{tabular}{|l|l|}
\hline GROUP & GASTRIC JUICE $\mathbf{p H}$ \\
\hline C & $3,28 \pm 0.11$ \\
\hline I & $3.57 \pm 0.09$ \\
\hline CI & $3.36 \pm 0.12$ \\
\hline TI & $3.14 \pm 008$ \\
\hline GI & $\mathbf{2 . 6 0} \pm 0.08^{\mathbf{b}}$ \\
\hline NI & $3.10 \pm 0.16$ \\
\hline NGI & $2.51 \pm 0.13$ \\
\hline
\end{tabular}

$C=$ control group, $I=$ non pretreated indomethacin group, $C I=$ cimetidine pretreated indomethacin group, $T I=$ tween 80 pretreated indomethacin group, $G I=$ glibenclamide pretreated indomethacin group, $N I=$ nicorandil pretreated indomethacin group and NGI = nicorandil and glibenclamide pretreated indomethacin group. $b=$ Significantly different from $I$ at $p<0.05$ and $d=$ Significantly different from NI at $p<0.05$. Values represent the mean \pm SEM for 10 observations.

TABLE (4): Effect of indomethacin (40 mg/ $\mathrm{kg}$, SC) on gastric juice free and total acid concentration and its alteration by various pre-treatments

\begin{tabular}{|c|c|c|}
\hline GROUP & FAC $(\mathbf{m E q} / \mathbf{L})$ & TAC (mEq/L) \\
\hline $\mathrm{C}$ & $28.9 \pm 1.22$ & $39.5 \pm 2.83$ \\
\hline I & $24.1 \pm 1.63$ & $35.7 \pm 2.11$ \\
\hline CI & $26.7 \pm 1.41$ & $39.5 \pm 1.54$ \\
\hline TI & $32.0 \pm 2.04$ & $41.5 \pm 3.31$ \\
\hline GI & $70.1 \pm 6.32^{\mathrm{a}, \mathrm{b}, \mathrm{c}, \mathrm{d}}$ & $80.2 \pm 5.83^{\mathrm{a}, \mathrm{b}, \mathrm{c}, \mathrm{d}}$ \\
\hline NI & $31.1 \pm 3.56$ & $42.0 \pm 3.83$ \\
\hline NGI & $70.5 \pm 6.91^{\mathrm{a}, \mathrm{b}, \mathrm{c}, \mathrm{d}}$ & $90.0 \pm 2.51^{a, b, c, d}$ \\
\hline
\end{tabular}

$C=$ control group, $I=$ non pretreated indomethacin group, $C I=$ cimetidine pretreated indomethacin group, $T I=$ tween 80 pretreated indomethacin group, $G I=$ glibenclamide pretreated indomethacin group, $N I=$ nicorandil pretreated indomethacin group, NGI = nicorandil and glibenclamide pretreated indomethacin group, FAC = free acid concentration and TAC = total acid concentration. $a=$ Significantly different from $C$ at $p<0.05, b=$ Significantly different from $I$ at $p<$ 0.05, $c=$ Significantly different from CI at $p<0.05$ and $d=$ Significantly different from NI at $p<0.05$. Values represent the mean \pm SEM for 10 observations. 
TABLE (5): Effect of indomethacin (40 mg/kg, SC) on gastric juice pepsin concentration and its alteration by various pre-treatments

\begin{tabular}{|l|l|}
\hline GROUP & PEPSIN CNCENTRAION $(\mu \mathrm{g} / \mathrm{ml}$ TYROSINE $)$ \\
\hline C & $\mathbf{1 4 0}+\mathbf{1 1 . 2}$ \\
\hline I & $194+5.58$ \\
\hline CI & $227+19.9$ \\
\hline TI & $231+15.7$ \\
\hline GI & $\mathbf{2 3 7 + 1 8 . 8}$ \\
\hline NI & $\mathbf{1 8 5}+\mathbf{1 2 . 2}$ \\
\hline NGI & $\mathbf{1 7 4 + 1 5 . 3}$ \\
\hline
\end{tabular}

$C=$ control group, $I=$ non pretreated indomethacin group, $C I=$ cimetidine pretreated indomethacin group, $T I=$ tween 80 pretreated indomethacin group, $G I=$ glibenclamide pretreated indomethacin group, $N I=$ nicorandil pretreated indomethacin group and NGI = nicorandil and glibenclamide pretreated indomethacin group. Values represent the mean \pm SEM for 10 observations.

TABLE (6): Effect of indomethacin (40 $\mathrm{mg} / \mathrm{kg}, \mathrm{SC})$ on gastric juice mucin concentration and its alteration by various pre-treatments

\begin{tabular}{|l|l|}
\hline GROUP & MC $(\mathrm{mg} / \mathrm{dl})$ \\
\hline C & $96.9 \pm 6.52$ \\
\hline I & $97.5 \pm 3.98$ \\
\hline CI & $92.6 \pm 6.28$ \\
\hline TI & $93.3 \pm 7.96$ \\
\hline GI & $44.6 \pm 4.12^{\text {a,b,c,d }}$ \\
\hline NI & $92.5 \pm 4.84$ \\
\hline NGI & $\mathbf{5 3 . 0} \pm 4.80^{\text {a,b,c,d }}$ \\
\hline
\end{tabular}

$C=$ control group, $I=$ non pretreated indomethacin group, $C I=$ cimetidine pretreated indomethacin group, $T I=$ tween 80 pretreated indomethacin group, $G I=$ glibenclamide pretreated indomethacin group, $N I=$ nicorandil pretreated indomethacin group, NGI = nicorandil and glibenclamide pretreated indomethacin group and $M C=$ mucin concentration. $a=$ Significantly different from $C$ at $p<0.05$, $b=$ Significantly different from I at $p<0.05, c=$ Significantly different from CI at $p$ $<0.05$ and $d=$ Significantly different from NI at $p<0.05$. Values represent the mean \pm SEM for 10 observations. 
TABLE (7): Effect of indomethacin (40 mg/kg, SC) on gastric mucosal lipid peroxides concentration and its alteration by various pre-treatments.

\begin{tabular}{|l|l|}
\hline GROUP & LIPID PEROXIDES ( $\eta$ mol /g WET TISSUE) \\
\hline C & $22.7 \pm 2.17$ \\
\hline I & $23.3 \pm 1.62$ \\
\hline CI & $18.2 \pm 1.69$ \\
\hline TI & $23.4 \pm 1.63$ \\
\hline GI & $18.6 \pm 1.40$ \\
\hline NI & $\mathbf{2 1 . 8} \pm 1.21$ \\
\hline NGI & $17.4 \pm 1.18$ \\
\hline
\end{tabular}

$C=$ control group, $I=$ non pretreated indomethacin group, $C I=$ cimetidine pretreated indomethacin group, $T I=$ tween 80 pretreated indomethacin group, $G I=$ glibenclamide pretreated indomethacin group, $N I=$ nicorandil pretreated indomethacin group and NGI = nicorandil and glibenclamide pretreated indomethacin group. Values represent the mean \pm SEM. for 10 observations.

TABLE (8): Effect of indomethacin (40 mg/kg, SC) on gastric mucosal histamine concentration and its alteration by various pre-treatments.

\begin{tabular}{|l|l|}
\hline GROUP & GM HISTAMINE $(\mu \mathrm{g} / \mathrm{g}$ WET TISSUE $)$ \\
\hline C & $194 \pm \mathbf{1 4 . 8}$ \\
\hline I & $159 \pm 6.91$ \\
\hline CI & $130 \pm 9.65$ \\
\hline TI & $217 \pm 10.5$ \\
\hline GI & $173 \pm 17.6$ \\
\hline NI & $231 \pm 18.2^{\mathbf{b}}$ \\
\hline NGI & $227 \pm 7.31^{\text {b }}$ \\
\hline
\end{tabular}

$C=$ control group, $I=$ non pretreated indomethacin group, $C I=$ cimetidine pretreated indomethacin group, $T I=$ tween 80 pretreated indomethacin group, $G I=$ glibenclamide pretreated indomethacin group, $N I=$ nicorandil pretreated indomethacin group, NGI = nicorandil and glibenclamide pretreated indomethacin group and GM = gastric mucosal. $b=$ Significant different from I at $p<0.05$. Values represent the mean \pm SEM for 10 observations. 
TABLE (9): Effect of indomethacin $\left(40 \mathrm{mg} / \mathrm{kg}\right.$, SC) on gastric mucosal PGE $_{2}$ concentration and its alteration by various pre-treatments

\begin{tabular}{|l|l|}
\hline GROUP & GM PGE $_{2}(\eta g / g$ WET TISSUE $)$ \\
\hline C & $346 \pm 33$ \\
\hline I & $233 \pm 21.4^{\mathrm{a}}$ \\
\hline CI & $237 \pm 19.7$ \\
\hline TI & $239 \pm 18.5$ \\
\hline GI & $272 \pm 23.9$ \\
\hline NI & $159 \pm 6.91$ \\
\hline NGI & $251 \pm 24.2$ \\
\hline
\end{tabular}

$C=$ control group, $I=$ non pretreated indomethacin group, $C I=$ cimetidine pretreated indomethacin group, $T I=$ tween 80 pretreated indomethacin group, $G I=$ glibenclamide pretreated indomethacin group, $N I=$ nicorandil pretreated indomethacin group, NGI = nicorandil and glibenclamide pretreated indomethacin group, $G M=$ gastric mucosal and $P G=$ prostaglandin. $a=$ Significant different from $C$ at $p<0.05$.Values represent the mean \pm SEM for 10 observations.

TABLE (10): Effect of indomethacin (40 mg/kg, SC) on gastric mucosal nitrites content and its alteration by various pre-treatments

\begin{tabular}{|l|l|}
\hline GROUP & GM NITRITES ( $\eta$ mol /g WET TISSUE) \\
\hline C & $\mathbf{1 6 8} \pm 14$ \\
\hline I & $165 \pm 10.9$ \\
\hline CI & $204 \pm 19.4$ \\
\hline TI & $209 \pm 20.7$ \\
\hline GI & $194 \pm 18.1$ \\
\hline NI & $249 \pm 20^{\text {b }}$ \\
\hline NGI & $253 \pm 24.9^{\mathbf{b}}$ \\
\hline
\end{tabular}

$C=$ control group, $I=$ non pretreated indomethacin group, $C I=$ cimetidine pretreated indomethacin group, $T I=$ tween 80 pretreated indomethacin group, $G I=$ glibenclamide pretreated indomethacin group, $N I=$ nicorandil pretreated indomethacin group, NGI = nicorandil and glibenclamide pretreated indomethacin group and $G M=$ gastric mucosal. $b=$ Significant different from $I$ at $p<0.05$. Values represent the mean \pm SEM for 10 observations. 


\section{DISCUSSION}

The present investigation was an attempt to study the possible involvement of $\mathrm{K}_{\mathrm{ATP}}$ channels, nitric oxide, histamine, free radical scavenging and $\mathrm{PGE}_{2}$ in the mechanism underlying the anti-ulcer activity of a unique $\mathrm{K}_{\mathrm{ATP}}$ channel opener and nitric oxide donor, nicorandil, in indomethacin-induced ulcers in adult male albino rats. The choice of utilizing indomethacin as an ulcer model was not only because NSAIDs-induced gastropathies are very common, but also because they have a different pathophysiology than the usual stress models and it is simple, rapid and effective in producing ulcers. NSAIDs, e.g., indomethacin, are among the most common agents that induce gastropathies, including ulcers, in humans. The pathophysiology of indomethacin-induced ulcers is less acid-dependent than stress ulcers ${ }^{\mathbf{1 8}}$. The relative importance of acid in indomethacin-induced ulcer model could be illustrated by the extent of protection afforded by cimetidine in the present study and others ${ }^{19}$.

Gastric hypermotihty seems to be a very important factor in the pathogenesis of indomethacin-induced ulcers $^{\mathbf{2 0}}$. The mechanism underlying the enhanced gastric motility probably involves vagal excitation, as it is inhibited by vagotomy or atropine administration $^{21}$.The ability of indomethacin to inhibit prostaglandin synthesis is undoubtedly a contributing factor ${ }^{22}$. Other factors include neutrophil adherence to microvascular endothelium, causing obstruction of blood flow to the mucosa predisposing it to injury. In addition, neutrophil activation/infiltration leads to release of reactive oxygen species (ROS) which damage the endothelium ${ }^{23}$. Indomethacin, also, was found to increase the synthesis of proinflammatory molecules, like TNF- $\alpha$ and $\mathrm{LTB}_{4}$, which also contribute to mucosal injury ${ }^{24}$. NSAID are known to cause mucosal barrier breaking ${ }^{25}$. A role for apoptosis in indomethacininduced gastropathy was suggested upon observing that this drug induced apoptosis of gastric mucosal cells, by activating apoptotic factors such as KAPSIS and BAX and inhibiting antiapoptotic factors, such as survivin ${ }^{26}$.

In the present work, administration of indomethacin (40 mglkg, s.c.) induced ulcerative lesions in the glandular portion of the rats stomachs which is in accordance with the findings of Eliott et al. ${ }^{4}$. Indomethacin did not significantly alter gastric juice volume or acid secretion parameters. Gastric acid secretion has been reported to be increased $^{27}$, decreased ${ }^{28}$ or unaltered ${ }^{21}$ by indomethacin administration. Although indomethacin was reported to initially increase gastric acid secretion, acid back diffusion was reported to occur afterwards ${ }^{29}$ leading to an apparent decrease or no change (if the back-diffusion was less severe) in gastric juice acidity as compared to the control group. In the present work, indomethacin did not significantly alter gastric juice pepsin concentration, which is in agreement with the observations of Khattab et al. ${ }^{27}$. 
Fiorucci et al. ${ }^{30}$, in their in vitro study, reported that indomethacin caused a significant calciumdependent increase in pepsinogen secretion from isolated chief cells and suggeste that indomethacin increases pepsinogen secretion by increasing leukotrienes synthesis.

Mucin concentration was not significantly altered by indomethacin treatment. Similar results were reported by Khattab et al. $^{27}$. Although NSAIDs are known to decrease gastric mucin synthesis disrupting the mucus-bicarbonate layer and then the gastric epithelial barrier, this does not lead to a significant effect on the adherent mucus layer nor the soluble mucin in the gastric juice in acute settings (as was employed in the present study).

In the present study, gastric mucosal lipid peroxides level was not significantly altered by indomethacin treatment, which is in agreement with the observations of Alican et al. ${ }^{31}$. However, several researchers reported that indomethacin significantly elevated gastric mucosal lipid peroxides level ${ }^{32,33}$.

In the present investigation, indomethacin did not significantly alter gastric mucosal histamine level, which agrees with the observations of Ericsson et al. ${ }^{34}$ and suggested that histamine is not probably a target for indomethacin gastric injurious action. In the present work, indomethacin significantly reduced gastric mucosal $\mathrm{PGE}_{2}$ level, which agrees with the previous reports and with the known mechanism of action of indomethacin as a non selective cyclooxygenase inhibitor ${ }^{33,34}$.

Gastric mucosal level of nitrites, in the current study was not significantly altered by indomethacin, a finding which is in agreement with that of Khattab et al. ${ }^{27}$.

Intra peritoneal administration of nicorandil significantly protected against ulcer formation and reduced ulcer index to $6.36 \pm 0.4$. cimetidine reduced the ulcer index to $6.17 \pm 0.24$. on the other hand, glibenclamide, when given one hour before indomethacin administration at a dose of $6 \mathrm{mg} / \mathrm{kg}$, did not significantly alter gastric lesions induced by indomethacin.

Concomitant administration of glibenclamide with nicorandil completely abolished the gastroprotective effect of nicorandil, this provides further support not only to the involvement of $\mathrm{K}_{\mathrm{ATP}}$ channel opening property of nicorandil in its anti-ulcer activity, but also to the presence of additional mechanisms of gastroprotection afforded by nicorandil, more evidently by opening $\mathrm{K}_{\text {ATP }}$ channels may act to augment the gastric defensive mechanisms that operate at least partly through these channels ${ }^{10}$.

In the current work, nicorandil did not significantly alter gastric juice volume or the acid secretion parameters beyond that produced by indomethacin, while cimetidine significantly reduced gastric juice volume. These results do not essentially negate an effect on gastric acidity by nicorandil and cimetidine. What probably has happened is that indomethacin, initially and as has been previously reported ${ }^{30}$, may have increased gastric acid secretion leading to a decrease in $\mathrm{pH}$ of gastric juice. This was followed by gastric 
barrier break and acid back diffusion elevating the $\mathrm{pH}$ again ${ }^{29}$.

Glibenclamide pre-treatment significantly increased gastric juice volume and acid secretion parameters. These results are due to blockade of the action of some acid suppressors or bicarbonate stimulators that operates through $\mathrm{K}_{\text {ATP }}$ channels like calcium gene related peptide (CGRP), adrenomodulin and $\mathrm{PG}^{\mathbf{1 0}}$ leading to an increase in acid secretion that outweigh the acid back diffusion leading to a net increase in gastric juice acidity. However, such changes were not accompanied by a significant difference in ulcer index between glibenclamide treated and non pretreated indomethacin groups, which may support the suggestion that gastric acid secretion is not the milestone in the pathogenesis of indomethacin-induced gastric ulcer ${ }^{18}$. Co-administration

of glibenclamide with nicorandil produced results similar to those observed with glibenclamide pre treated group as regards to the volume of gastric juice and the acid secretion parameters, which means that glibenclamide could have antagonized such effects, if any, of nicorandil on these parameters.

In the current investigation, neither cimetidine, nor nicorandil altered significantly gastric juice mucin concentration. Meanwhile, glibenclamide pre-treatment markedly decreased mucin concentration, alone and when combined with nicorandil. This was explained to be due to the partial blockade of the gastroprotective effect of PG by blocking $\mathrm{K}_{\mathrm{ATP}}$ channels ${ }^{\mathbf{1 0}}$, as $\mathrm{PG}$ are known to be potent stimulators of mucus secretion $^{35}$.

In the present study, none of the pre-treatments significantly altered gastric mucosal peroxides levels, which indicates that free radical scavenging property of nicorandil does not contribute to its gastric protective activity in this model of ulceration.

The results of the current study clearly demonstrate that administration of nicorandil significantly increased gastric mucosal histamine. This implies that histamine is probably not a target for nicorandil'gastroprotective effects and that $\mathrm{K}_{\mathrm{ATP}}$ channels probably do not influence histamine release. Similar to the effect of nicorandil on pepsin secretion, increased NO released from nicorandil could be responsible for increased gastric mucosal histamine, as NO was reported to stimulate histamine release from the isolated gastric mucosal cells ${ }^{36}$.

Gastric mucosal $\mathrm{PGE}_{2}$ level was not significantly altered by nicorandil in the indomethacin ulcer model. This negates an effect of nicorandil and, subsequently, $\mathrm{K}_{\text {АTP }}$ channels on gastric mucosal $\mathrm{PGE}_{2}$ content in this ulcer model. This does not exclude any modulating effect for nicorandil on $\mathrm{PGE}_{2}$ activity since prostaglandins were reported to produce their gastroprotective effects, at least partly, through opening of $\mathrm{K}_{\mathrm{ATP}}$ channels ${ }^{10}$. Therefore, nicorandil is expected to augment $\mathrm{PGE}_{2}$ activity by further opening of these channels.

In the present study, nicorandil was found to increase significantly gastric mucosal nitrites level. The increase in gastric mucosal nitrites was associated with a significant 
mitigation of the indomethacininduced ulcers even when the $\mathrm{K}_{\mathrm{ATP}}$ channel opening property of nicorandil was blocked by glibenclamide, denoting a significant role for NO in the gastroprotective action of nicorandil.

Several researchers have reported the gastroprotective effects of Larginine, the immediate precursor of NO, and NO-donors in indomethacin-induced ulcers ${ }^{37,38,27}$. Additionally, several NO-releasing NSAIDs have been synthesized and were found to be not only less ulcerative than conventional NSAIDs, but also to be gastroprotective against other noxious substances $\mathbf{3 9 , 4 0}^{\mathbf{3}}$.

In summary, the present data highlight a gastroprotective effect for nicorandil in the indomethacin model, the mechanism of which probably involves $\mathrm{K}_{\mathrm{ATP}}$ channel opening and $\mathrm{NO}$ donation.

\section{REFERENCES}

1. Bose, M.; Motghare, V.; Dakhale, G. and Turankar, A. (2003): Antiulcer activity of leveromakalim and nicorandil in albino rats: a comparative study. Pol. J. Pharmacol., 55: 91-95.

2. Whittle, B.; Lopez-Belmonate, J. and Moncada, S. (1990): Regulation of gastric mucosal integrity by endogenous nitric oxide: Interactions with prostanoids and sensory neuropeptides in the rat. $\boldsymbol{B r}$. $\mathbf{J}$. Pharmacol., 99: 607-611.

3. Takeuchi, K.; Furukawa, O.; Tanaka, H. and Ueki, S.(1986): A new model of duodenal ulcers induced by indomethacin and histamine. Gastroenterology, 90:
636-645.

4. Elliott, S.; Ferris, R.; Giraud, A.; Cook, G.; Skeljo, M. and Yeomans, N. (1996): Indomethacin damage to rat gastric mucosa is markedly dependent on luminal $\mathrm{pH}$. Clin. Exp. Pharmacol. Physiol., 23: 432-444.

5. Saika, M.; Akima, M. and Katsuyama, I. (1999) : Effects of nicorandil on experimentally induced gastric ulcers in rats: a possible role of K(ATP) channels. Jpn. J. pharmacol., 79: 51-57.

6. Toroudi, H.; Rahgozar, M.; Bakhtiarian, A. and Djahanguiri, B. (1999): Potassium channel modulators and indomethacin-induced gastric ulceration in rats. Scand. J. Gastroenerol., 34: 962-966.

7. Patel, H.; Santani, D. and Goswami, S. (2001): Evaluation of the effects of nicorandil on experimentally induced gastric ulcers. Pharmacology, 63: 154159.

8. Garrick, T.; Buack, S. and Bass, P. (1986): Gastric motility is a major factor in cold restraintinduced lesion formation in rats. Am. J. Physiol., 250: G191G199.

9. Alumets, J.; Klund, M. and Hakanson, R. (1982): Gastric acid response to pyloric ligation in rats. J. Physiol., 323: 145-146.

10. Peskar, B.; Ehrich, K. and Peskar, B. (2002): Role of ATPsesetive potassium channels in prostaglandin-mediated gastroprotection in the rat. $\boldsymbol{J}$. Pharmacol. Exper. Ther., 301: 969-974. 
11. Ohkawa, H.; Ohishi, N. and Yagi, K. (1979): Assay for lipid peroxides in animal tissues by thiobarbituric acid reaction. Anal. Biochem., 95: 351-358.

12. Shore, P.; Burkhalter, A. and Cohn, V. (1959): A method for the flourometric assay histamine in tissues. J. Pharmacol. Exp. Ther., 127: 182-186.

13. Kiuchi, Y.; Isobe, Y.; Kijima, H.; Saito, T. and Higuchi, S. (1998): Role of nitric oxide and prostaglandin in the protective effect of pibutidine hydrochloride, a novel histamine $\mathrm{H} 2$ receptor antagonist, on the gastric mucosal lesions in rats. Gen. Pharmacol., 31: 271-275.

14. Moor, E. (1968): Determination of $\mathrm{pH}$ by glass electrode: $\mathrm{pH}$ meter calibration for gastric analysis. Gastroenterology, 54: 501-509.

15. Hara, N.; Hara, Y. and Goto, Y. (1991): Gastric hyperacidity and mucosal damage caused by hypothermia correlated with increased GABA concentration in the rat brain. EUR. J. Pharmacol., 194: 77-81.

16. Sanyal, A.; Debnath, P.; Bhattachary, S. and Gode, K. (1971): The effect of cyproheptadine on gastric activity. Peptic ulcer, Pfeffer, C.J. Copenhagen, Denmark, Munkesgaard. 312-318.

17. Bhavanandan, V.; Sheykhnazari, M. and Devarj, H. (1990): Colorimetric determination of Nacetylhexozamine-terminating $\mathrm{O}$ glycsidically linked saccharides in mucin and glycoproteins. Anal. Biochem., 188 : 172-184.

18. Wallace, J. (2001): Pathogenesis of NSAID-induced gastroduodenal mucosal injury. Best. Pract. Res. Clin. Gastroenteropl., 15: 691-703.

19. West, G. (1982): Testing for drugs inhibiting the formation of gastric ulcers. J. Pharmacol. Methods, 8: 33-37.

20. Ueki, S.; Takeuchi, K. and Okabe, S. (1988): Gastric motility is an important factor in the pathogenesis of indomethacin-induced gastric mucosal lesions in rats. Dig. Dis Sci, 33: 2009-2116.

21. Takeuchi, K.; Kato, S.; Nishiwaki, H. and Hirata, T. (1997): Analysis of pathogenic elements involved in gastric lesions induced by non-steroidal anti-inflammatory drugs in rats. J.Gastroenterol. Hepatol., 12: 360-367.

22. Ferraz, J. and Wallce, J. (1997): Underlying mechanisms of portal hypertensive gastropathy. J. Clin. Gastroenterol, 25 (suppl 1): S73S78.

23. Beck, P.; Xavier, R.; Lu, N.; Nanda, N.; Dinawer, M.; Podolsky, D. and Seed, B.(2000): Mechanism of NSAIDinduced gastrointestinal injury defined using mutant mice. Gastroenterology, 119: 699-705.

24. Appleyard, C.; McCafferty, D. and Tigley, A. (1996): Tumor necrosis factor mediation of NSAID-induced gastric damage: role of leukocyte adherence. Am. J. Physiol., 270: G42-G48

25. Hawkey, C. (2000): Nonsteroidal 
anti-inflammatory

drug

gastropathy. Gasteroenerology, 119: 521-535.

26. Chiou, S.; Tanigawa, T.; Akahoshi, T.; Abdelkarim, B.; Jones, M. and Tarnawski A. (2005): Survivin: a novel target for indomethacin-induced gastric injury. Gastroenterology, 128(1): 63-73.

27. Khattab, M.; Gad, M. and Abdallah, D. (2001): Protective role of nitric oxide in indomethacin- induced gastric ulceration by a mechanism independent of gastric acid secretion. Pharmacol. Res., 43: 463-467.

28. Nicolof, D. (1968): Indomethacin: effect on gastric secretion, parietal cell population and ulcer provocation in dogs. Arch. Surg., 97: 809-815.

29. Lin, T.; Warrick, M.; Evans, D. and Nash, J.(1975): Action of the anti-inflammatory agents: acetylsalicylic acid, indomethacin and fenoprofen on the gastric mucosa of dogs. Res. Commun. Chem. Pathol. Phrmacol., 11: 114.

30. Fiorucci, S.; Santucci, L.; Gresele, P.; Luinetti, $O$. and Morelli, A. (1995): Effect of NSAIDs on pepsinogen secretion and calcium mobilization in isolated chief cells. Am. J. Physiol., 268: G968-G978.

31. Alican, I.; Coskun, T.; Corak, A.; Yegen, B.; Oktay, S. and Kurtal, H. (1995): Role of neutrophils in indomethacininduced gastric mucosal lesions in rats. Inflamm. Res., 44: 164168.
32. Takeuchi, K.; Takehara, K. and Ohuchi, T.(1996):

Diethyldithiocarbamate, a superoxide dismutase inhibitor, reduces indomethacin-induced gastric lesions in rats. Digestion, 57: 201-209.

33. Hassan, A.; Martin, E. and Puig-Parellada, P. (1998): Role of antioxidants in gastric mucosal damage induced by indomethacin in rats. Methods Find. Exp. Clin. Pharmacol., 20: 849-854.

34. Ericsson, P.; Norlen, P.; Bernsand, M.; Alm, P.; Hoglund, P. and Hakanson, R. (2003): ECL cell histamine mobilization studied by gastric submucosal microdialysis in awake rats: methodological considerations. Pharmacol. Toxicol., 93: 57-65.

35. Wallace, J. and Ma, L. (2001): Inflammatory mediators in gastrointestinal defense and injury, Exp. Biol. Med. (Maywood), 226: 1003-1015.

36. Hasebe, K.; Horie, S.; Yano, S. and Watanabe, K. (2003): Stimulatory effects of nitric oxide donors on histamine release in rat gastric mucosal cells. Boil. Pharm. Bull., 26: 950-953.

37. Brazozoweski, T.; Konturek, S.; Sliwowski, Z.; Drozdowicz, D.; Zaczek, M. and Kedra, D. (1997): Role of L-arginine, a substrate for nitric oxidesynthase, in gastroprotection and ulcer healing. J. Gastroproenerol, 32: 442-452.

38. Mourad, F.; Khuri, M.; Shouaib, F. and Nasser, C. (2000): Protective effect of the nitric oxide donor molsidomine 
on indomethacin and aspirininduced gastric injury in rats. Eur. J. Gastroenterol. Hepatol., 12: 81-84.

39. Fiorucci, S.; Santucci, L.; Gresele, P.; Faccino, R.; Del Soldato, P. and Morclli, A. (2003): Gastrointestinal safety of NO-aspirin (NCX-4016) in healthy human volunteers: a proof of concept endoscopic study. Gastroenterology, 124: 600-607.

40. Konturek, P.; Brozozoweski, T.; Kania, J.; Konturek, S. and Hahn, E. (2003): Nitric oxide releasing aspirin protects gastric mucosa against ethanol damage in rats with functional ablation of sensory nerves. Inflamm. Res., 52: 359-365.

\section{المفعول الحامي للغشاء المخاطي للمعدة لعقار النيكور انديل ضد إصابات المعدة المستحدثة بالإندوميثاسين}

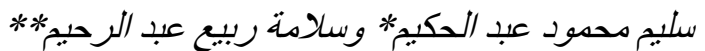

من قسمي الفسيولوجي* و الكيمياء الحيوية*** ـ كلية الطب جامعة الرجية المنيا

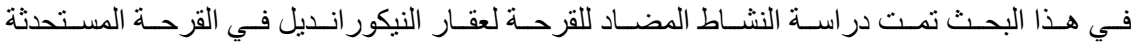

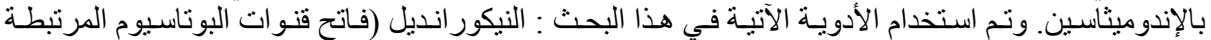

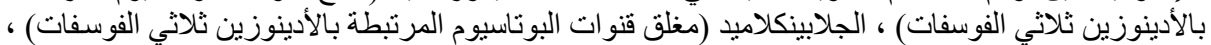

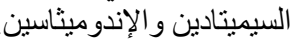

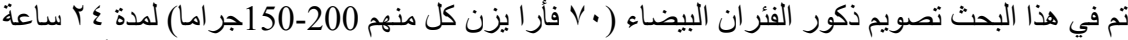

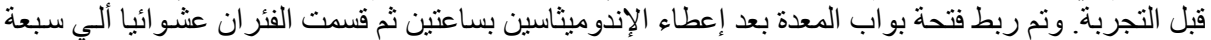

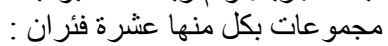

1ـ المجموعة الضابطة: وفيها تركت الفئر ان تتجول بحرية في أقفاصـها بعد ربط فتحسة البو اب لجمع العصـارة

r ا مجموعة الإندوميثاسين الغير معاملة: حيث حقنت بالإندو ميثاسين بجر عة مقدار ها ـ ـ مجم/كجم تحت الجلا.

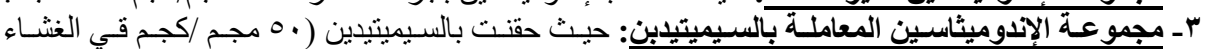

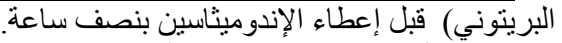

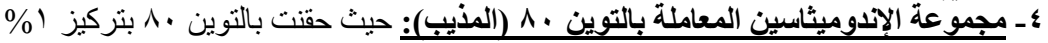

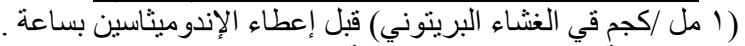

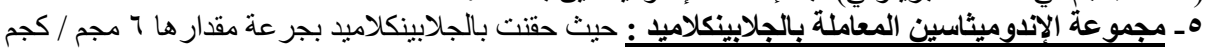

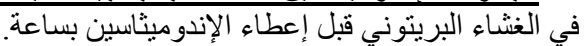

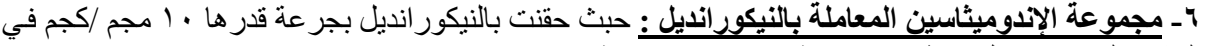

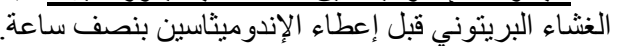

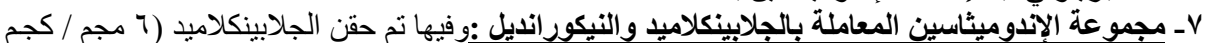

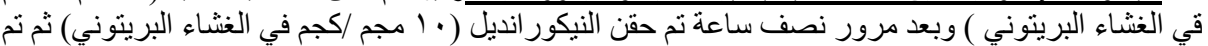

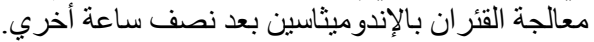

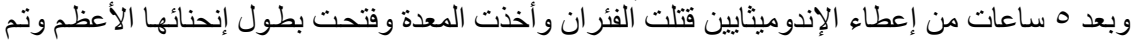

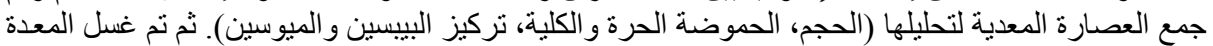

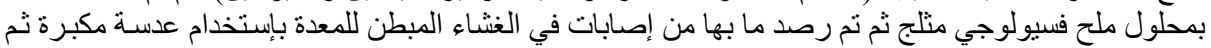


تم حفظ المعدة بالتبريد عند درجـة ـ • م م حتي تم قياس بيروكسيدات الدهون و الهيتامين و البرستاجلاندين

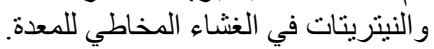

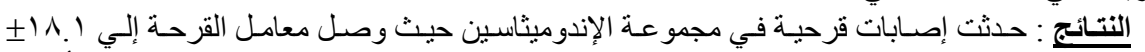

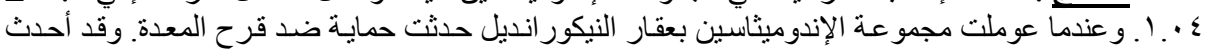

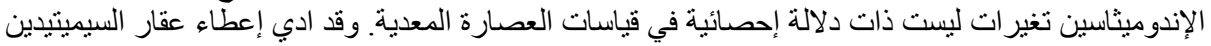

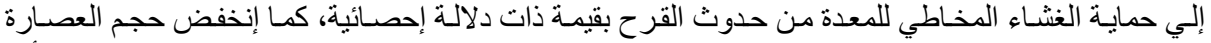

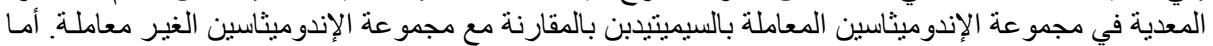

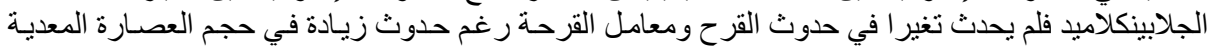

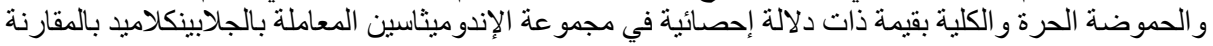

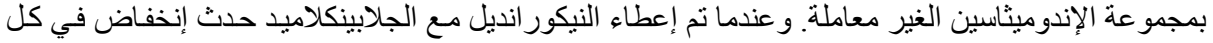

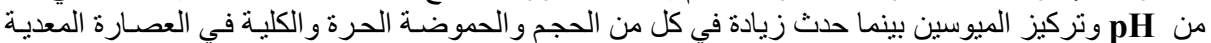

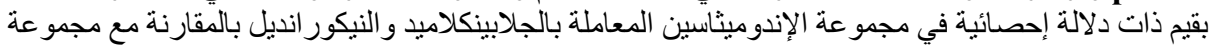
الإندوميثاسين الغير معاملة.

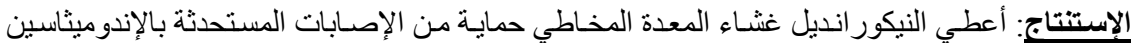

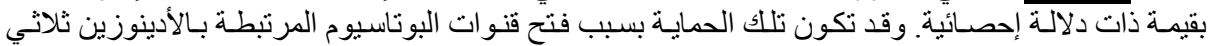

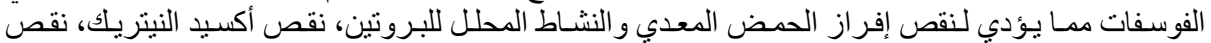

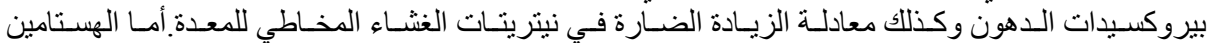

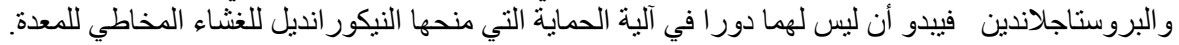

